\section{Sri Lankan J. Biol. 2021, 6 (1): 1 - 2

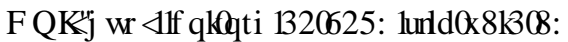 \\ KUSVIIRLFIGTRUT0000-0002-5086-0215}

Editorial

Open Access

\title{
Water: Panacea, Pearl and Problem Child
}

${ }^{1 *}$ Gunawardana, D.

${ }^{1}$ Research Council, University of Sri Jayewardenepura, Sri Lanka.

*Corresponding author: dilanthag12@gmail.com or dilantha@sci.sjp.ac.lk

To the chemist, it is a compound made of two elements forming a weak intermolecular interaction, producing a unique type of bond halfway between electrostatic and covalent bonds; to the biologist, it is an elixir of vitality that gives form to cells, a medium for life, and electron donation for photosynthesis; to the physicist, it is about melting and boiling points that define many phenomena; to the engineer it is an opportunity to build a dam and to harness hydroelectricity; to the climate change specialist it is a greenhouse gas; to the virologist, it is a stagnant reservoir that supports proliferation of mosquito vectors that transmits dengue viral fever, to the meteorologist it is rainfall, the abundance and lack of it, such as the monsoons in places like India and the absence of it in the Atacama Desert; for those wannabes of Elon Musk, it is a stout indicator of life; and for the average man, it is the vital cog that determines, the dhal curries we cook, the excretory products that we flush, the donor of a body to blood in circulation, the cleanser of our bodies after a hard day's work. Water is omnipresent and utilityready to most of us, but if you travel to Darfur or South Sudan or parts of India, this valuable resource can have a rare presence, where water from the heavens - or the earth - is just as much a Rain-God Indra-branded luxury good. The message is, water is now a strategic empirical science and is no longer the sound of pitter-patter in the choreography of raindances or palms interfaced in devotion.

To the scientific community, it is the quieter and more junior partner to a more violent "climate change", that is just as precious and vital from a protectionist angle, thereby making the world a more livable place. We should remember that climate change and water are interlinked in many ways, from being the vehicle of cyclones, the crucial missing consistency to drought, the deficiency which provides favorable conditions for ruthless wildfires, the hailstorms that can cause more damage than meteors, the floods and landslides that can leave footprints of mortality and provoke higher counts of morbidity, thereby gifting an unbearable burden on the public health care system. In a nutshell, water can be both beneficial and wasteful; for example, being the liberator of oxygen gas in photosynthesis, as well as being the scapegoat of lost harvests due to submergence intolerance.

In this bittersweet picture, we should be detailing out how we can use products aimed at economizing water to help civilization. This can be done in many angles. For example, the introgression of a Submergence Tolerance Quantitative Trait Locus (QTL) to a susceptible variety of rice developed by the International Rice Research Institute (IRRI) scientists, led to the conception of a submergence tolerance rice variety, which has the potential to tolerate up to 3 weeks of submergence stress. In addition, new methods such as vertical farming removes to a significant extent, the water-use footprint of a plant, which can be a useful outcome for the more frugal use of water in farming. Hydroelectricity harnesses the potential of water for the production of electricity, which a few decades back was one of the primary methods by which Sri Lankan households were gifted with electricity. There are also drought tolerant grains such as chickpea, cowpea, pigeon pea, and other legumes, which have been developed by the International Crops Research Institute for the SemiArid Tropics (ICRISAT) for the reinforcement of drought stress tolerance in such semi-arid/arid crops. There is also a viable window of opportunity to strategically genetically-engineer those proteins called "aquaporins" in plants - of which the discovery resulted in the Nobel Prize for Chemistry in 2003 being awarded to esteemed molecular biologist, Peter Agre, the pioneer in the field of aquaporins to facilitate the transport of water, with greater fluidity, precision and to negate at best, water and salt stresses. We too are now actively preserving wetlands and the wealth of biodiversity embedded in such water-opulent ecosystems, being signatories of conventions such as 
Ramsar, Iran, in 1971. Sri Lanka is the first country to protect the entirety of its mangrove forests, and thus sets a precedent for other countries to follow.

While organizations such as the International Water Management Institute based in Sri Lanka, a sleepless workhorse at the grassroots level to economize water usage, and to improve water productivity, while being sensitive to the human toll; mortalities and morbidities of water-propagated communicable diseases is a realistic frontier. Desalination too is slowly emerging to drive home the message that seawater is too an enterprise where innovation can build a resolute picture of water armed with utility. The reuse of industry effluents, by using biotreatment and phytoremediation at the hands of microbes and plants, is a viable bio-friendly investment in research. Water ferns such as members of the genus Azolla (growing in paddy fields), can be used to sanitize the irrigation water from heavy metal pollutants, namely chromium, cadmium and lead. The pollutants are hyperaccumulated inside plant compartments, and thus precludes the storage of such metals inside irrigated rice so preventing contamination of food chains. Furthermore, we need to find real-world solutions to macro- and micro-plastic pollution of waterways by isolating bacteria such as Ideonella sakaiensis that is able to degrade some forms of plastic, namely poly ethylene terephthalate (PET) into simpler reaction products.

Water has been a problem child to Sri Lanka. Sri Lanka along with a few other countries scattered across the world, though primarily from Central and Latin America, have experienced CKDu (Chronic Kidney Disease of an Unknown etiology), which has been also given terminology such as Chronic Agricultural Nephropathy or Chronic Kidney Disease from a multifactorial origin. The etiology is thought of as either singular or integrative, and the prevalence is as high as $21-23 \%$ in some districts of Sri Lanka. The etiology is thought to be water, specifically, what is contained in water; cadmium and other heavy metals, fluoride, cyanotoxins such as Microcystin, pesticides, impure fertilizers and other factors associated with water that impacts the human kidneys. It has been demonstrated that the prevalence of $\mathrm{CKDu}$ is significantly higher in areas where there are shallow wells found in close proximity to irrigated paddy fields, which could transfer nephrotoxic compounds to shallow wells and consequently, drinking water. Females are more susceptible than males to CKDu (62 versus $38 \%$ ) and this predicament was more common in those with comorbidities such as hypertension (63\%), while a subset too had diabetes. Still, the quality of water is the primary criterion, and consequently, many mechanisms proposed and acted upon to remediate CKDu are water-related - reverseosmosis (RO) water-treatment plants and nanofiltration (NF) membrane technologies.

Sri Lanka too is battered by seasonal drought in the growing seasons that local scientists are now investigating the root properties to shed light on traditional landraces that are better able to seek, find and use long-distance water sources and so are better able to handle drought or water stress. The root system of any plant is responsible for water capture and thus screening for such “drought-friendly" root characteristics are of great interest. Root angle, root biomass, root anatomy, root length and root distribution are all important factors for water uptake in drought-prone environments.

Water as a whole should not be thought of as a pearl, but a limited agent that should be used and re-used, while keeping an eye on the stocks of freshwater at hand. The aboriginal community in the Australian continent, who are known for their resilient survival skills dating back to their migratory origins 50000 years ago, focuses on sources of water, and a process called "soakage", which means that it is possible to dig out the mud/sand, to find a subsurface layer of water beneath. It is said that their indigenous knowledge is vital for the identification of "water sprouts". The future is one of technology helped by indigenous practices and combined we can make water a part of an endearing circular economy. Astute water management is not a bridge too far; nor is it something to saunter on. It is fair to see the future landscape with fear and trepidation, and it is getting worse each year. Action is the requirement of the hour, with the "how" empowered by investments in primary research.

They say that God-gifted manna is found inside the Ark of the Covenant, which is hidden somewhere inside a holy city (like Axum/Aksum) in Ethiopia. I too read about how aerobic rice varieties are grown in well drained soils in Ethiopia, marking another wonderful fairytale of a water-scarce world. We don't need to chase the Holy Grail; we just need to be pragmatic in our water economies. Manna in 2020 is what we make out of the parsimonious resources we have, including that of freshwater; which too happens to fall from the downpouring heavens. 